\title{
Simplification or Accuracy: In Assessing Functional Outcomes After Intersphincteric Resection for Low Rectal Cancer
}

\author{
Kyung Jong Kim \\ Department of Surgery, School of Medicine, Chosun University, Gwangju, Korea
}

\section{See Articles on Page 148-154}

It is a great pleasure to review the article titled "Early and Late Functional Outcomes of Anal Sphincter-Sparing Procedures With Total Mesorectal Excision for Anorectal Adenocarcinoma" [1]. The authors report excellent postoperative outcomes, only $10.6 \%$ of fecal incontinence and $58 \%$ of normal anal tone after intersphincteric resection (ISR) for very low rectal cancer.

In 1994, Schiessel et al. [2] first report ISR for very low rectal tumor, which dissects intersphincteric plane with removal of the internal sphincter and bowel continuity is restored by coloanal anastomosis, instead of traditional abdominoperineal resection. However, this extreme operation raises 2 major concerns, local recurrence, and anorectal dysfunction. In a review of ISR for lowlying rectal cancer, the local recurrence rate ranged from $0 \%$ to $12 \%$ [3], which results seem like acceptable. But in terms of bowel dysfunction after ISR, the functional outcomes showed very complicated with a wide range, $0 \%$ to $75.9 \%$ of major fecal incontinence $[3,4]$. The common symptoms after ISR were an inability to get to the toilet in time, sense of incomplete evacuation, and fragmentation of defecation. In the review of anal dysfunction after ISR, preoperative chemoradiotherapy consistently represents an independent risk factor $[3,5,6]$. But in this article, neoadjuvant therapy did not affect postoperative continence outcome, instead male sex, tumor location less than $3 \mathrm{~cm}$ from anal verge, tumor T-stage, total resection of the internal anal sphincter, and oc-

Correspondence to: Kyung Jong Kim, M.D.

Department of Surgery, School of Medicine, Chosun University, 365 Pilmundaero, Dong-gu, Gwangju 61453, Korea

Tel: +82-62-220-3068, Fax +82-62-228-3441

E-mail: kjkim@chosun.ac.kr

ORCID: https://orcid.org/0000-0001-8984-2180

(C) 2020 The Korean Society of Coloproctology

This is an open-access article distributed under the terms of the Creative Commons Attribution NonCommercial License (https://creativecommons.org/licenses/by-nc/4.0) which permits unrestricted noncommercial use, distribution, and reproduction in any medium, provided the original work is properly cited. currence of postoperative colonic stenosis were correlated with poor continence function.

The reason of wide range of bowel dysfunction after ISR seems to be multifactorial including patient factors and measurement methods. Low anterior resection syndrome score, Wexner incontinence score, Memorial Sloan Kettering Cancer Center score, and Kirwan grade are usually used for subjectively assessing functional outcomes after ISR. Of these, Kirwan grade is the most simple, others are somewhat complex for scoring. Also, anorectal manometry and dynamic magnetic resonance imaging (MRI) can be used as an objective tool for assessing anal function after ISR. But in spite of relative high cost and time-consuming procedures, these tools have a little serious disadvantage, for example, operator dependent for anorectal manometry and poor correlation to patient-reported symptom for dynamic MRI [5].

The authors assess anal tone after ISR using the per-anal examination scoring system (PASS), which is modified from DRESS (digital rectal examination scoring system) [7]. The PASS is simply divided 5 grades of postoperative anal function: grade 1 (extremely hypotonic sphincter), grade 2 (slightly hypotonic), grade 3 (normal tone), grade 4 (slightly stenotic), and grade 5 (occluded anal canal). This method seems to be very simple and easy to use. But there is a risk of inter-observer variation.

Currently, there is no standard method for assessing bowel function after ISR, although this operation inevitably causes bowel dysfunctions. It is essential to develop standard method for assessing not only objective anal function, but also patient-reported outcomes.

\section{CONFLICT OF INTEREST}

No potential conflict of interest relevant to this article was reported.

\section{REFERENCES}

1. Eldamshety O, Kotb S, Khater A, Elnahas W, Roshdy S, Zahi MS 
et al. Early and late functional outcomes of anal sphincter-sparing procedures with total mesorectal excision for anorectal adenocarcinoma. Ann Coloproctol 2020;39:148-54.

2. Schiessel R, Karner-Hanusch J, Herbst F, Teleky B, Wunderlich M. Intersphincteric resection for low rectal tumours. Br J Surg 1994; 81:1376-8.

3. Park IJ, Kim JC. Intersphincteric resection for patients with lowlying rectal cancer: oncological and functional outcomes. Ann Coloproctol 2018;34:167-74.

4. Sakr A, Yang SY, Kang JH, Cho MS, Han YD, Min BS, et al. Oncologic safety and bowel function after ultralow anterior resection with or without intersphincteric resection for low lying rectal can- cer: Comparative cross sectional study. J Surg Oncol 2020;121: 365-74.

5. Collard M, Lefevre JH. Ultimate functional preservation with intersphincteric resection for rectal cancer. Front Oncol 2020;10:297

6. Battersby NJ, Juul T, Christensen P, Janjua AZ, Branagan G, Emmertsen KJ, et al. Predicting the risk of bowel-related quality-oflife impairment after restorative resection for rectal cancer: a multicenter cross- sectional study. Dis Colon Rectum 2016;59: 270-80.

7. Orkin BA, Sinykin SB, Lloyd PC. The digital rectal examination scoring system (DRESS). Dis Colon Rectum 2010;53:1656-60. 